\title{
Designing A Solar and Motor-Based Hybrid Powered Mobile Sprinkler System for Small-Scale Irrigation: A Case Study for Auchi Polytechnic Demonstration Farm
}

\author{
Okafor Michael $\mathrm{C}^{1}$. Suleiman Ibrahim Abubakar ${ }^{2} \quad$ Fatimah Parker Ikharo ${ }^{2}$ \\ 1.Department of Civil Engineering Technology, Auchi Polytechnic, Auchi, Edo State, Nigeria \\ 2.Department of Agricultural and Bioenvironmental Engineering, Auchi Polytechnic, Auchi, Edo State, Nigeria
}

\begin{abstract}
This research aimed at developing a model of a hybrid-powered sprinkler irrigation system for use in the town of Auchi, Nigeria, a town with costly and intermittent electricity access. As a highly agrarian society, it is vital that market gardens developed by the family have access to water to provide their families with food and income from the selling of the crops. In Nigeria, changes in rainfall patterns are posing a threat to crop output. Irrigation can be utilized to maintain consistent production; however, motorized irrigation systems are both expensive to operate and environmentally unsustainable. Alternative watering methods are consequently required. Irrigation systems can be powered by readily available renewable energy sources. In order to irrigate 1 acre of vegetable planting in Auchi Polytechnic Demonstration Farm, Auchi, Nigeria, this research sought to design an effective Generator-solar hybrid system. The Using metrological data, mean wind speed and monthly solar irradiance of global radiation horizontal for the district were analysed. The mobile hybrid sprinkler system was optimally designed for a vegetables plant on 1-acre land with water requirement of $33.73 \mathrm{~m}^{3} \mathrm{~d}^{-1}$. The results upon fabrication showed that the system could effectively operate at speeds of $20 \mathrm{~m} \mathrm{~s}^{-1}$ without deformation. The research will, therefore, be a useful guideline in making investment decisions in hybrids irrigation systems.
\end{abstract}

Keywords: Automated, Irrigation, Auchi Polytechnic Demonstration Farm, hybrid-powered sprinkler

DOI: $10.7176 / \mathrm{ISDE} / 12-4-01$

Publication date:October $31^{\text {st }} 2021$

\section{Introduction}

Agriculture employs almost 78 percent of Nigeria's population, making it the country's economic backbone. Climate change and fluctuation, on the other hand, have continued to have an impact on crop and livestock output, making these economic undertakings unreliable. Irrigation has the ability to tackle water and food security issues caused by climate change. Irrigation, on the other hand, necessitates both energy and water to function. Water and energy are two interconnected industries, with a $40 \%$ rise in energy consumption expected to lead to a $30 \%$ increase in water demand(Couto et al., 2013). These high energy demands hence make irrigation adoption limited economically especially to the majority of smallholder farmers who earn less than a dollar per day(Ssenyimba et al., 2020). Renewable energy irrigation pumps are becoming more popular as a solution to the problem of over-reliance on the conventional grid and motorized irrigation pumps(Ssenyimba et al., 2020). Apart from hydropower, there is a growing trend in Nigeria to look into alternative renewable energy sources to help the country's burgeoning industrial sector(Bodunde et al., 2019). Nigeria's convective diesel or petrol and electrical water pumping systems are being replaced by solar and wind water pumping, which is a viable option. This is due to the country's equatorial environment, which features plenty of sunshine and moderate wind speeds. Further industrial development will be attributed to reliable and high-quality energy sources and this will constitute a substantial increase in quality of life for Nigerian citizens(Adeodu et al., 2019; Rahman et al., 2014a).

Developing and implementing environmentally sound renewable energy technologies will aid in the modernization of agriculture. However, using a renewable energy resource system as a stand-alone system may result in in operation at certain times of the day and seasons, as well as unnecessary operational and lifecycle costs and component oversizing(Adeodu et al., 2019; Rahman et al., 2014a). These constraints can be solved by combining two or more renewable energy resources, such as a solar system and a generator, into a hybrid system(Rahman et al., 2014a; Ssenyimba et al., 2020). A hybrid system has the advantage of improved reliability and gives better energy service when compared to a standalone supply system(Rahman et al., 2014b; Ssenyimba et al., 2020). Designing renewable energy hybrid systems involves sizing and selecting the best components to provide affordable, efficient and effective renewable energy(Ssenyimba et al., 2020).Therefore, a hybrid power system that is cost- effective, none polluting and reliable was proposed to mitigate the scarcity of electricity for crop irrigation in Auchi Polytechnic Demonstration Farm. However, there is scanty scientific information on the utilization of solar-Generator hybrid systems to meet irrigation energy requirement in Nigeria. Thus, the main objective of this study was to access the potential and viability of a Generator-solar hybrid sprinkler irrigation system using Auchi Polytechnic Demonstration Farm as a case study. 
Water A sprinkler system is a device that distributes water in a spray to irrigate a lawn or garden in a home setting. Sprinklers can be quite big, like the irrigation systems used by professional farmers, or they can be relatively tiny, like the normal lawn or garden watering sprinklers and fire suppression systems(Rahman et al., 2014a). Retired people spend more time gardening than others, thus a sprinkler would be great in this instance. However, sprinkler use is still fairly limited in residential areas throughout Africa (Nigeria, for example) and Asia. The use of sprinklers has a positive effect on garden/crop etc. which is evident as several authors reviewed development on this area. The objective of this paper is to analyse the technology and application of Hybrid Sprinkler System in Nigeria and its scope in the future. First, the paper provides the method used, findings and the analysis in determining how to fabricate the hybrid sprinkler system. Secondly, the paper provides a background on hybrid sprinkler technology in Nigeria with respect to international standards. Third, the designing and fabrication of a mobile hybrid sprinkler is briefly discussed. The final section contains the prospects, recommendations and conclusion of the mobile hybrid sprinkler system in Nigeria.

\section{Sprinkler Technology}

Automatic sprinkler systems are made up of a network of water pipelines connected to automatic sprinkler heads, which are devices that open and release water in a predetermined pattern and density across a defined area. Sprinkler systems save water by spreading it uniformly and efficiently, compared to manual methods. Sprinkler technology is rapidly growing on the international market, and one reason for this is the necessity to conserve natural resources (water). Water sprinklers in a variety of styles and patterns, as well as sophisticated devices, are easily accessible. The manufacturing companies nowadays are trying to achieve(Rahman et al., 2014a):

$>$ Greater throw distance

$>$ Targeted watering

$>$ Operation in freezing conditions

$>$ Quick-change nozzle systems

$>$ Modularity, etc.

Sprinklers with high-tech gadgets/devices increases its efficiency and effectiveness. According to Rahman et al., (2014a) some of them are:

$>$ Water sense labelled controllers - These are weather based controllers that uses local data to determine whether the sprinkler system needs to be turned on.

$>$ Soil Moisture Sensors - Some smart controllers use soil moisture sensors to water when the soil becomes too dry. It stops watering when the soil is wet.

$>$ Rainfall Shutoff Devices - Rainfall shutoff devices turn off the system in rainy weather and help compensate for natural rainfall. This inexpensive device can be retrofitted to almost any system.

$>$ Sprinkler Heads - Certain types of sprinkler heads apply water more efficiently than others. Rotary spray heads deliver water in a thicker stream than mist spray heads, ensuring more water reaches plants and less is lost to evaporation and wind.

$>$ Micro-Irrigation-Micro-irrigation or drip systems are generally more efficient than conventional sprinklers because they deliver low volumes of water directly to plants' roots, minimizing the water lost to wind, runoff, evaporation, or overspray.

In comparison to all of these, the Nigerian market for an automatic sprinkler system is far behind. The presence of high-tech gadgets and equipment, let alone the availability of water sprinklers (lawn), is fairly limited. Watering the garden and lawns is usually done by hand, using garden showers or hoses, which wastes a lot of water, time, and energy. Many people are unaware that appropriate and effective technology exist. Few sprinklers on the market are made in other nations and have simple designs with few improvements to improve their efficiency. In this location, there are no water sprinklers. However, according to the report, sprinkler use might be considerably increased if sprinklers were made freely available and at reasonable prices.

\section{Survey}

\subsection{Questions, Solution and Results}

The findings, information gathered, and analysis performed are all based on the survey results. People were selected at random to participate in the survey and provide crucial input. The survey was done both online and in person and consisted of a set of 23 questions (objective) with 21 adapted from Rahman et al., (2014a). Some of the questions put on the survey are as follows:

$>$ Do you know about water sprinkler?

$>$ Do you know water sprinkler waters the farm more effectively than by other means?

$>$ Would you be willing to change to the water sprinkler to water or vegetable or small-scale farm?

$>$ Would you want sensors/timers/high-tech gadgets along with the water sprinkler at the sacrifice of price?

$>$ Would you want to buy the hybrid water sprinklers which are made in Nigeria?

$>$ In buying a water sprinkler, does brand value affect you? 
$>$ Does aesthetics matter for buying a water sprinkler?

$>$ Are you interested in knowing how you can incorporate such hybrid system into your farm?

The survey's results were gathered, and all of the responses were analyzed and summarized in order to gain a better understanding of the consumers' perspectives, demands, and impressions. Summarized bar charts were made for each question, indicating the respective percentages of each answer. These offered critical information for prioritizing client wants, which ultimately helped in the design of a water sprinkler.

\subsection{Survey challenges, discussions, validation}

One of the primary challenges encountered throughout the survey was that only about $20 \%$ of Nigerians were aware of hybrid water sprinklers system before to the poll. This may be due to a lack of interest in using renewable energy as a power source in agricultural areas. To address this, we decided to provide a brief explanation of a typical hybrid sprinkler system before to conducting the survey, aiding and validating it to some extent. The online poll, which was only accessible to a small fraction of Nigerians due to the low number of internet users, is another source of concern.

\subsection{Survey analysis}

The major outcomes from the survey found are: Cost effectiveness, Corrosion/Wear resistance, Light Weight, Portability, Aesthetics, Ease of Maintenance, Coverage, Quality and Longevity of the Sprinklers.

\subsection{Design and Fabrication}

The proposed design of hybrid sprinkler involved materials which included a 300-W PV panel, Prime mover $(0.5$ hp motor + pump), Sprinkler heads, risers, Pipe works (PVC + Stainless Steel), Thermocouples and mild steel sheets have been purchased and installed. Other materials such as filtration system, flush valves, regulators are encapsulated under sprinkler heads and installed. The automation of the sprinkler system and solar powered battery pack and the generator formed the hybrid power system. The Figures 4.1-4.5 showed the AUTOCAD draft of the system and entire fabrication phase of the work.

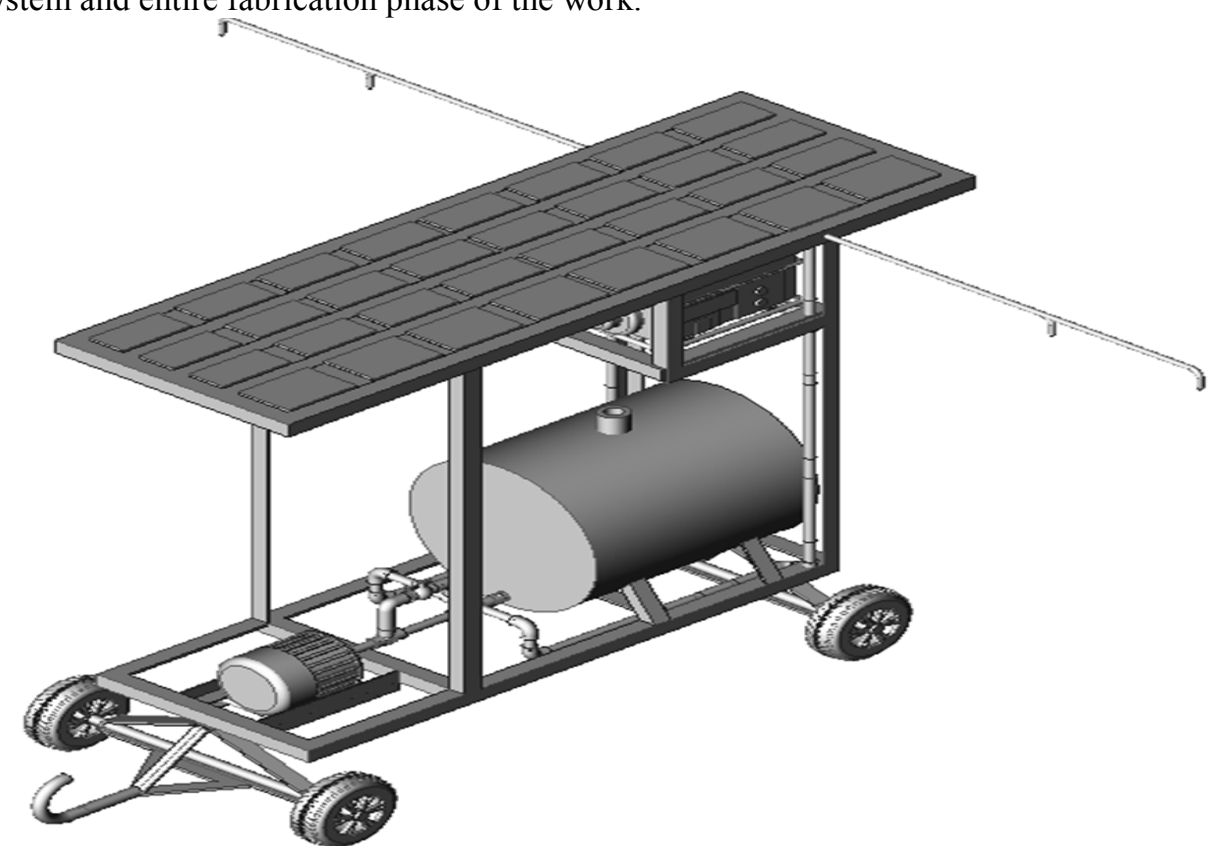

Figure 4.1: The orthographic view of the mobile hybrid sprinkler 


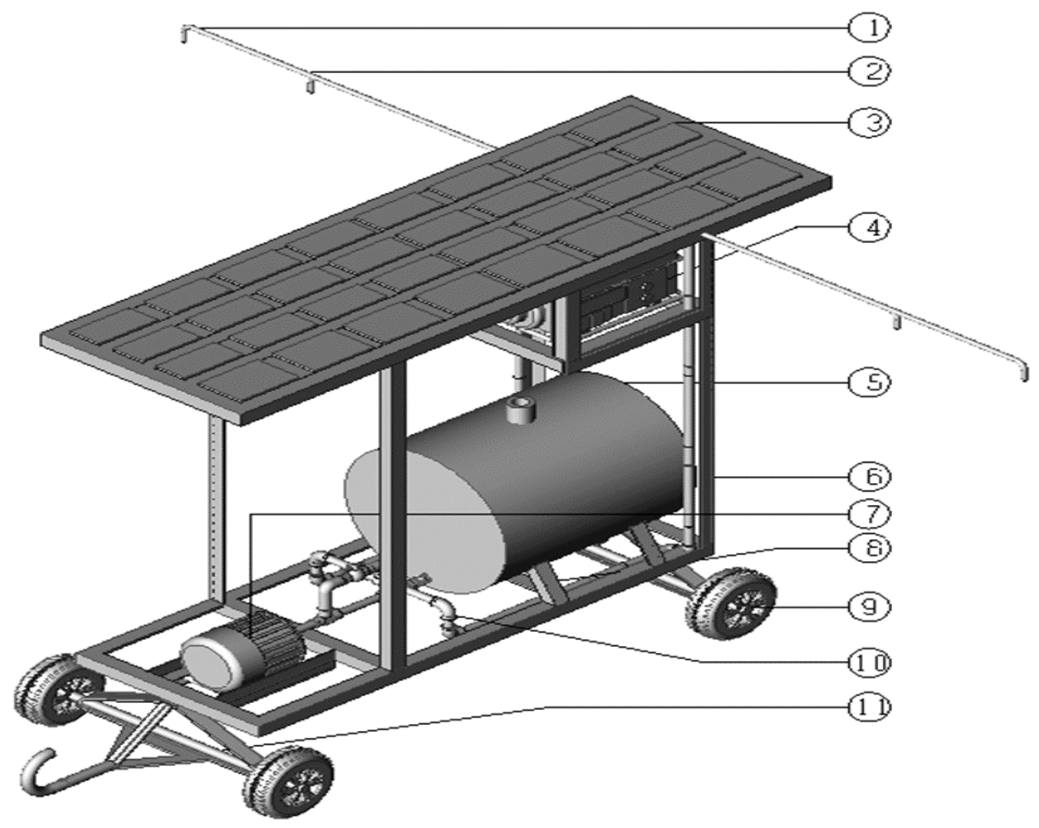

Figure 4.1: Using the Orthographic View to show the different parts of the Mobile Hybrid Sprinkler Sprinkler Pipe

Sprinkler Nozzle

Solar Panel

Generator/Battery Bank Unit

Tank

Solar Panel Support

Pump

Frame (Base)

Roller

Pipe Network

Drawbar

The base remains fixed and the water flows in through it via water piping system. The bolt is screwed with the base by means of screw thread system which allows the rotary cylindrical stem (lower), passing through it, and the rotary cylindrical stem (upper) to rotate with respect to the base. Three nozzles each bent into three different angles vertically (approximately $10^{\circ}, 12^{\circ}$ and $14^{\circ}$ ) to achieve uniform coverage. The spray head converts the incoming water into sprays. An automated timer circuit mechanism, which is basically a timeresponsive releasing mechanism for watering areas following a fixed pattern and time interval, has been connected to automate the watering to a certain degree. The pictorial views for the system during fabrications are shown in figure 4.3-4.5 


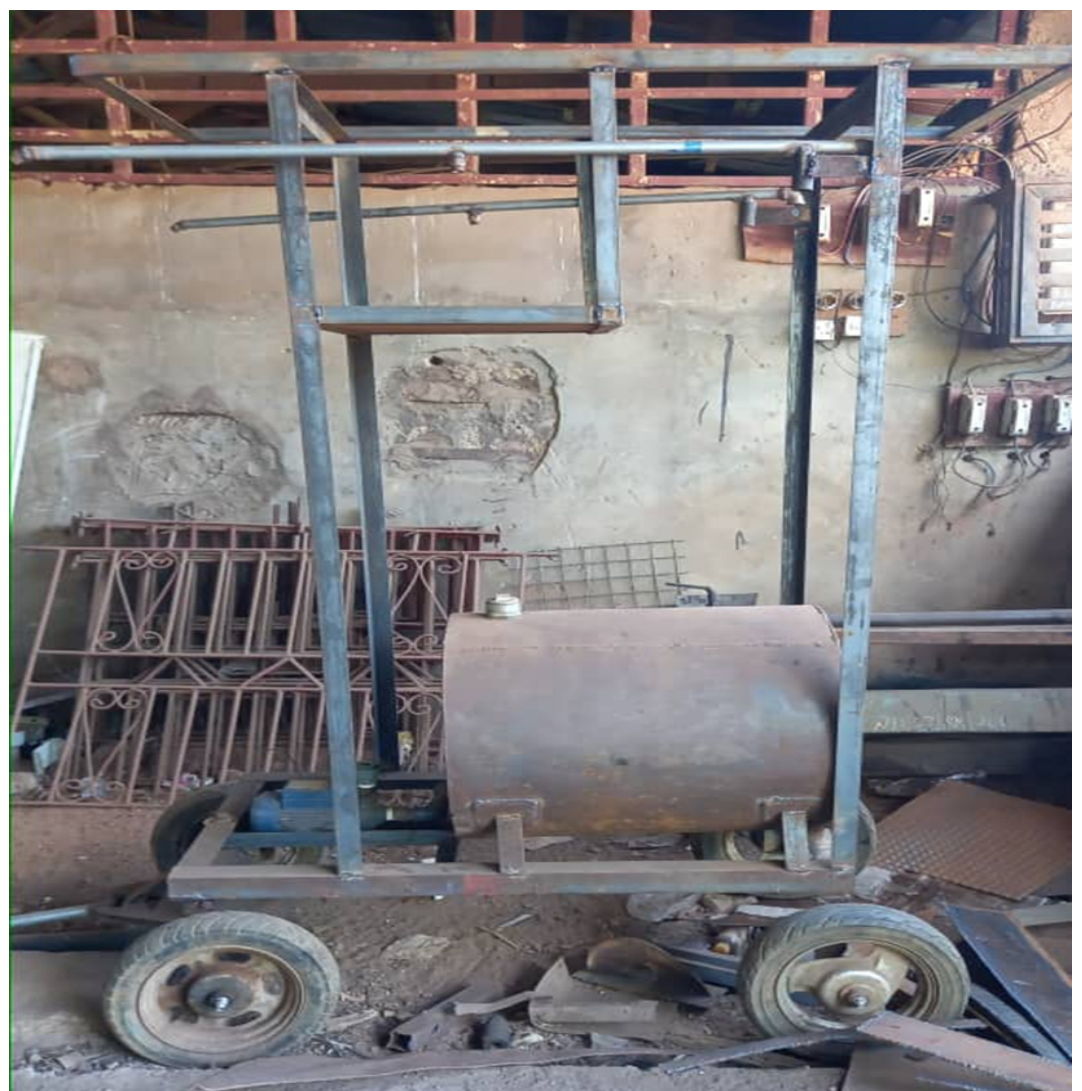

Figure4.3: Side View of the Hybrid Sprinkler System Under Fabrication

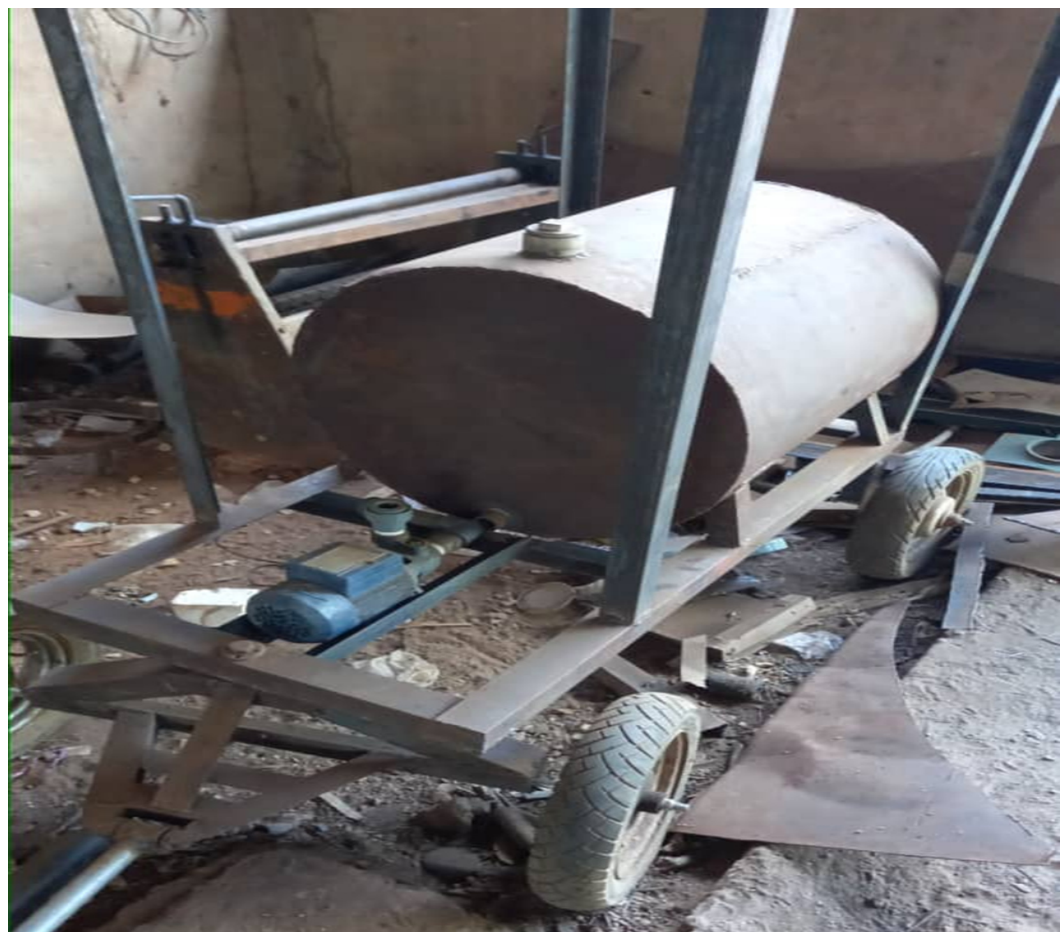

Figure 4.4: Front View Showing the Pump and Tank sections

For the fabrication of the water Sprinkler standard engineering methods involving Material Selection, Manufacturing Process Selection and Black Box Diagram were followed. Material used to be Mild Steel for the Lower Body (Base) and the rest from Brass. The manufacturing process involved is as shown in Table 1. 


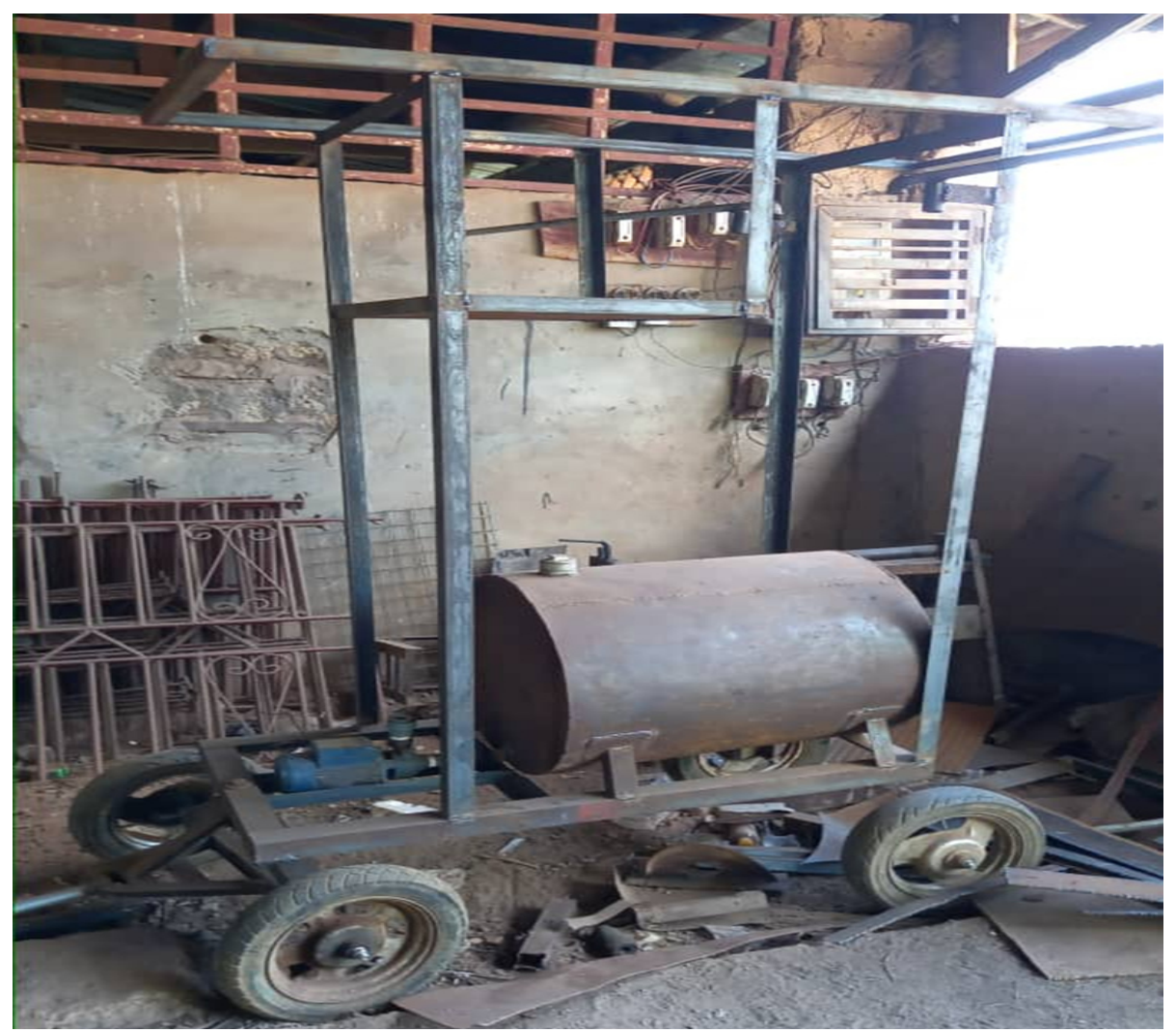

Figure 4.5: Extended Side View of the Hybrid Sprinkler System Under Fabrication

Table 1. Fabrication processes

\begin{tabular}{|l|l|}
\hline Name of Parts & Fabrication Process \\
\hline Lower Body (Base) & Shear cutting, metal joining and welding \\
\hline Solar System Frame & Cutting and joing of Angle Bars at required dimensions. \\
\hline Generator/Battery Bank Unit & $\begin{array}{l}\text { Cutting and joining of 1.5 mm Mild steel plate with angle } \\
\text { bars frame at required dimension. }\end{array}$ \\
\hline Tank & Cutting and turning of $2 \mathrm{~mm}$ mild steel plate \\
\hline Splinkler Pipe & Off-shelf \\
\hline $\begin{array}{l}\text { Splinkler Nozzele } \\
\text { Solar Panel }\end{array}$ & Off-shelf \\
\hline Roller & Off-shelf \\
\hline Pipe Network & \\
\hline Drawbar & Cutting, bending and welding of galvanized pipes \\
\hline
\end{tabular}

Various standard guidelines such as DFM (Design for Manufacturing), DFA (Design for Assembly) etc. has been followed to ensure the product is up to standard. The designed Hybrid Sprinkler will be tested in terms of its coverage, longevity, quality of spray produced, dispersing pattern of water etc. and compared with those available on market.

\section{Conclusion}

The hybrid sprinkler irrigation system has exhibited significantly higher potential for adoption but there is a challenge. This challenge is brought about by the fact that it will require constant motion and the mechanis guiding that is manually operated. However, the sprinkler systems are automated and as such shows potentials yield improvement can be mainly attributed to better soil moisture conditions that were further supported by strong relationships of crop yield with LAI, stem diameter, plant height, achene weight, HI, and aboveground biomass. Solar-Generator hybrid energy system is the most feasible economic solutions in lowering electricity costs for farmers practicing irrigation ariculture. It also avoids the high costs encountered during extending grid power lines to remote areas and provides a clean renewable non-polluting source of energy for the farms. In this paper, the water requirement for irrigating one acre of vegetables(pumpkin) in Auchi Polytechnic demonstration far will be used in further performance evaluation of the hybrid system. The determined, pipeline for the irrigation system and design layout made, power to meet the irrigation demand determined and a solar-generator 
hybrid system sized for supplying the required electric power for irrigation will be evaluated subsequently. The system was tested for flow behaviour, static pressure, turbulence intensity and stress at a speed, three times the average wind speed of Auchi Polytechnic Demonstartion Farm and the results showed that the system could still work properly without undergoing through deformation.

\section{Declaration of competing interest}

The authors declare that they have no known competing financial interests or personal relationships that could have appeared to influence the work reported in this paper.

\section{Acknowledgements}

This work was funded by the Institution Based Research Grant of Tertiary Education Trust Fund (TETFUND) in Nigeria.

\section{REFERENCES}

Adeodu, A. O., Bodunde, O. P., Daniyan, I. A., Omitola, O. O., Akinyoola, J. O., \& Adie, U. C. (2019). Development of an autonomous mobile plant irrigation robot for semi structured environment. Procedia Manufacturing, 35. https://doi.org/10.1016/j.promfg.2019.05.004

Bodunde, O. P., Adie, U. C., Ikumapayi, O. M., Akinyoola, J. O., \& Aderoba, A. A. (2019). Architectural design and performance evaluation of a ZigBee technology based adaptive sprinkler irrigation robot. Computers and Electronics in Agriculture, 160. https://doi.org/10.1016/j.compag.2019.03.021

Couto, A., Ruiz Padín, A., \& Reinoso, B. (2013). Comparative yield and water use efficiency of two vegetables hybrids differing in maturity under solid set sprinkler and two different lateral spacing drip irrigation systems in León, Spain. Agricultural Water Management, 124. https://doi.org/10.1016/j.agwat.2013.03.022

Rahman, A. ur, Zahura, M. T., \& Rezwan, A. (2014a). Simplified Design and Fabrication of Water Sprinkler System: A Survey Based Analysis. Procedia Engineering, 90. https://doi.org/10.1016/j.proeng.2014.11.796

Rahman, A. ur, Zahura, M. T., \& Rezwan, A. (2014b). Simplified Design and Fabrication of Water Sprinkler System: A Survey Based Analysis. Procedia Engineering, 90. https://doi.org/10.1016/j.proeng.2014.11.796

Ssenyimba, S., Kiggundu, N., \& Banadda, N. (2020). Designing a solar and wind hybrid system for small-scale irrigation: a case study for Kalangala district in Uganda. Energy, Sustainability and Society, 10(1). https://doi.org/10.1186/s13705-020-0240-1 